\title{
Bilateral Temporal Triangular Alopecia
}

\author{
Tas $\mathrm{B}^{1}$ and Pilanci $\mathrm{O}^{2}$
}

${ }^{1}$ Department of Dermatology, Bagcilar Research and Training Hospital, Turkey

${ }^{2}$ Department of Plastic, Reconstructive and Aesthetic Surgery, Bagcilar Research and Training Hospital, Turkey

\begin{abstract}
Temporal Triangular Alopecia (TTA) or Brauer nevus, is a circumscribed, non-scarring form of alopecia present over the temporal region. It is also known as hypotrichotic nevus. Approximately, 55 cases have been reported in literature. The lesion is usually unilateral and rarely occurs bilateral. Herein we present a 7-year-
\end{abstract} old male child with bilateral TTA.

\section{Introduction}

Temporal Triangular Alopecia or Brauer nevus (TTA) is a wellcircumscribed triangular or lancet-shaped area of non-cicatricial hypotrichosis positioned in the fronto-temporal area [1-4]. The lesion is permanent and asymptomatic [5]. It was first described by Sabouraud in 1905 [3,6]. In 1926, it was redefined by Brauer as a part of the Brauer's syndrome (Focal facial dermal displasia-type- $1=$ hereditary symmetrical aplastic nevi of temples, bitemporal aplasia cutis congenita) that is characterized by temporal skin depressions that resemble "forceps marks" [7].

\section{Case}

A 7 year-old-boy was presented with localized areas of diminished hair over the both temporo-parietal regions. The lesions had not been noticed because of he was born with hairless scalp. The parents of the patient first noticed the alopecic lesions at the third year of age. Since than, there were no changes in the appearance of hairless areas. None of the family members had similar hair loss. The patient had evaluated in the past, by different general practitioners as a case of alopecia areata and had been treated with topical and intra-lesional steroid without any improvement. There were no history of any intrauterine pressure, and an obstetric or an acquired trauma. There is no cutaneous defect at the alopecic areas. On dermatological examination, there were less and fine hairy triangular alopecic patches over the both temporoparietal regions (Figures $1 \mathrm{a}, 1 \mathrm{~b}$ and $1 \mathrm{c}$ ). Right patch was larger $(7 \times 9 \times 13 \mathrm{~cm})$ than the left one $(5 \times 7 \times 9 \mathrm{~cm})$. Dermatoscopic examination showed mostly vellus hairs and a small number of terminal hairs at the alopecic patches (Figure 1d). Between the triangular patches and frontal areas, there were small hair fringes. Any scaling, erythema, scarring or induration were not seen at alopecic areas. Exclamation

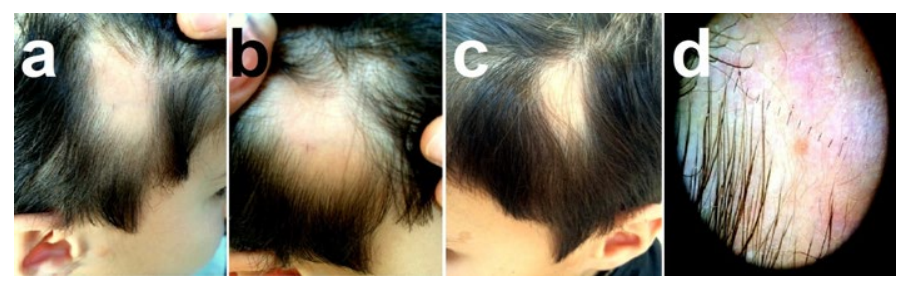

Figure 1. Clinical view of the typical triangular hypotrichotic patches with small fringes of terminal hair. a,b) Right alopecic patch (distand and closure views) c) Left alopecic patch d) Dermatoscopic view of the right alopecic patch. mark hairs were not seen. Hair pull test was negative at the both area. The dermatological examinations of the nails, mucosa, and the remaining physical examination were normal. Routine laboratory tests were normal. Trichogram or scalp biopsy could not be done because the parents did not give a consent. All of these findings suggested the diagnosis of "bilateral congenital temporal triangular alopecia".

\section{Discussion}

TTA is usually found on the frontotemporal area and affects only 1 side of the scalp [5] and usually manifests after two years of age when the vellus replaced by terminal hair $[1,3,4]$. Althought the frequency of the lesion is not known, some authors have reported a frequency of $0.11 \%$. It seems to affect both sexes equally. Previous cases have been reported mainly in whites, although there have also been cases among Asians and African-Americans [5]. The cause of TTA is so far unknown. It is unilateral in $80 \%$ of cases $[1,4,8]$ and it usually appears sporadically. However, it may occur within families as a paradominant trait $[3,8]$. Additionally, it has been argued that TTA may reflect a mosaicism. This entity usually occurs as an isolated anomaly but it may also be a part of a multisystemic birth anomalies such as serebellar-trigeminal-dermal dysplasia (Gomez-LopezHernandez (GLH) syndrome) or phacomatosis pigmentovascularis type-2 $[4,6]$. In the other hand the condition may occur as part of a syndrome with autosomal-dominant inheritance [9]. Rarely, the lesion may involve large temporoparietal area which can be a characteristic component of GLH syndrome (craniosynostosis, midfacial hypoplasia, trigeminal anesthesia, cerebellar dysplasia and mental deficiency) [5]. Our patient's lesions were sporadic and we did not detect any familial inheritance. Also, the lesions of the patient were not accompanied by any neurovascular or pigmentary disorders, and they were not parts of the Brauer's or GLH syndromes. Although rare reports of lesions in the occipital region have been reported, TTA usually affects the frontal and parietotemporal area. Clinically, it is characterized by finer

Correspondence to: Betul Taş, Department of Dermatology, Bagcilar Research and Training Hospital, Turkey, Atakoy 7-8. Kisim, Marti Sitesi, 14/105, Bakirkoy/Istanbul, Tel: (90) 212-4404000, Fax: (90) 212-4404000; E-mail: betulavc@yahoo.com

Received: November 28, 2014; Accepted: December 18, 2014; Published: December 20, 2014 
hair in a triangular area with blunt angles and the base of the triangle lying towards the hairline. Sometimes, the shape of the lesion is not exactly resemble a triangle, and can be ovoid or round [5]. Anterior margin of the lesions are sometimes separated from the lesion by a small fringe of normal hair [8], as in our patient. In the affected area, mostly vellus hairs, and occasionally a few terminal hairs are seen. The skin is normal $[4,6,8]$. Exclamation mark hairs are absent and hair pull test is negative [5]. Histopathologically, hair follicles are markedly miniaturized or absent $[6,8,9]$. We were unable to histopathological examination of the lesions because the parents did not allow for biopsy. However, the diagnosis of TTA is made based on clinical features $[4,6]$. A histopathology study is not usually necessary (munios). It should be differentiated primarily from Alopecia Areata (AA), and other patterned hairless lesions such as trichotillomania, tinea capitis, androgenetic alopecia and aplasia cutis [6]. Typical history, precocity, triangular shape, stability over time, poor response to topical steroids and lack of exclamation mark hairs help to distinguish it from AA $[4,6]$. The lesions of our patient had been noticed at the third year of age when the vellus replaced by terminal hair. He had the typical clinical and dermatoscopic features of TTA ( persistence of the lesions since third age, stable course, typical triangular shapes of the lesions, frontotemporal locations, presence of the small terminal hair fringe on the border of the frontal regions, absence of the exclamation mark hairs, the normal appearance of the epidermis in affected areas and presence of the mostly vellus hairs on the lesion). There is no specific treatment of this condition and it is not usually necessary [5]. However, the patient can benefit from complete excision of the affected area [6] or hair graft transplantation in the future $[3,4,6,10]$. Our case was presented for the raise awareness to the rare and unique lesion that very closely mimics alopcia areata. If physicians are aware of the condition, they can explain it to the parents, and patients can be protected from false diagnosis and improper treatments such as corticosteroids.

\section{References}

1. Trakimas CA, Sperling LC (1999) Temporal triangular alopecia acquired in adulthood $J$ Am Acad Dermatol 40: 842-844. [Crossref]

2. García-Hernández MJ, Rodríguez-Pichardo A, Camacho F (1995) Congenital triangular alopecia (Brauer nevus). Pediatr Dermatol 12: 301-303. [Crossref]

3. Gupta LK, Khare A, Garg A, Mittal A (2011) Congenital triangular alopecia: a close mimicker of alopecia areata. Int J Trichology 3: 40-41. [Crossref]

4. Tå̊Ÿ B, Pilanci Ã-, BaÅŸaran K (2013) Congenital temporal triangular alopecia: a typical Brauer nevus. Acta Dermatovenerol Alp Pannonica Adriat 22: 93-94. [Crossref]

5. León-Muiños E, Monteagudo B, Labandeira J, Cabanillas M (2008) Bilatera congenital triangular alopecia associated with congenital heart disease and renal and genital abnormalities. Actas Dermosifiliogr 99: 578-579.

6. Kudligi C, Bhagwat PV, Eshwarrao MS, Tandon N (2012) Giant congenital triangular alopecia mimicking alopecia areata. Int J Trichology 4: 51-52. [Crossref]

7. Cervantes-Barragan DE, Villarroel CE, Medrano-Hernandez A, Duran McKinster C, Bosch-Canto V, et al. (2011) Setleis syndrome in Mexican-Nahua sibs due to a homozygous TWIST2 frameshift mutation and partial expression in heterozygotes review of the focal facial dermal dysplasias and subtype reclassification. J Med Genet 48: 716-720.

8. Burgdorf WHC, Plewing G, Wolff HH, Landthaler M (2009) Braun-Falco's Dermatology. (3rdedtn). Diseases of hair. Springer Medizin Verlag, Heidelberg 10291059.

9. Ruggieri M, Rizzo R, Pavone P, Baieli S, Sorge G, et al. (2000) Temporal triangular alopecia in association with mental retardation and epilepsy in a mother and daughter. Arch Dermatol 136: 426-427. [Crossref]

10. Yamazaki M, Irisawa R, Tsuboi R (2010) Temporal triangular alopecia and a review of 52 past cases. J Dermatol 37: 360-362. [Crossref]

Copyright: (C2014 Tas B. This is an open-access article distributed under the terms of the Creative Commons Attribution License, which permits unrestricted use, distribution, and reproduction in any medium, provided the original author and source are credited. 